\title{
UM PARLAMENTO PARA O MERCOSUL: O PROCESSO POLÍTICO E HISTÓRICO DE SUA CRIAÇÃO
}

\author{
Elisa de Sousa Ribeiro* \\ Rafael Nascimento Reis
}

\section{Resumo}

O presente trabalho tem como objetivo analisar o caminho percorrido no âmbito do Mercosul até a criação de seu Parlamento Regional e apresentar as atividades que estão sendo desenvolvidas por este recente órgão. Antes de nos debruçarmos sobre o tema, realizaremos uma breve retrospectiva do movimento de integração dos países latino-americanos. Inicialmente, percebendo as tentativas bilaterais de promover acordos econômicos, passando pelas iniciativas de conformação de zonas de livre comércio e culminando no atual estado em que se encontra o Mercado Comum do Sul. Desta forma, será possível compreender a real importância que este órgão parlamentar tem para o Mercosul.

Palavras-chave: Relações Internacionais. Modelos de Integração Regional. Parlamento do Mercosul.

\section{Introdução}

A riqueza da América Latina consiste em ser tantas coisas ao mesmo tempo, o que faz dela um microcosmo no qual coabitam quase todas as raças e culturas do mundo. Esse amálgama é sua riqueza. Ser um continente que carece de identidade porque tem todas elas (LLOSA, s.n.).

\footnotetext{
* Bacharel em Direito pelo Centro Universitário de Brasília e Mestranda em Relações Internacionais.

** Bacharel em Direito pelo Centro Universitário de Brasília e Mestrando em Relações Internacionais.
} 
Estas palavras definem de forma magistral a realidade do continente sul-americano, formado por diferentes etnias e tradições culturais. Em meio a este sincretismo, nasceu em 26 de março de 1991, da união entre Argentina, Brasil, Uruguai e Paraguai, o Mercado Comum do Sul.

Quando de sua criação, adotou-se um modelo institucional no qual a condução do bloco concentrava-se na mão dos Poderes Executivos dos Estados Partes e a participação da sociedade se resumia à Comissão Parlamentar Conjunta e ao Foro Consultivo Econômico-Social. Ao longo dos anos, percebeu-se a necessidade de um órgão na estrutura do Mercosul que contemplasse a representação dos povos, a diversidade característica da América do Sul. Nesse sentido, após alguns anos de maturação e de um intenso trabalho técnico e político, foi criado o Parlamento do Mercosul.

Neste artigo, analisaremos o caminho percorrido pelo Mercosul, desde o Tratado de Assunção, até a criação deste recente órgão, com vistas a demonstrar o processo que levou ao seu nascimento.

\section{Princípio dos movimentos integracionistas no cone sul}

Pode-se dizer que Simon Bolívar, famoso revolucionário venezuelano, foi um dos precursores dos ideais integracionistas da América Latina. Sua célebre frase na qual diz que as nações do novo mundo devem estar unidas por um conjunto de leis comuns que regem suas relações externas, demonstra sua visão de vanguarda sobre o tema. No ano de 1815, Bolívar redigiu a Carta da Jamaica, marco inicial da tentativa de união da América Latina, que continha relatos do autor a respeito da conformação de um modelo de integração, mais especificamente, nos moldes de uma Confederação de Estados, que teria como finalidade e estabelecimento de 
uma zona de livre comércio. ${ }^{1}$ Não só na vida política, mas também no meio acadêmico, intelectuais como o chileno Andrés Bello e o argentino Juan Bautista Alberdi, ainda no século XIX, também idealizavam uma união dos povos da América do Sul. ${ }^{2}$

No âmbito das Nações Unidas, ano de 1948, foi criada a Comissão Econômica para a América Latina e Caribe (Cepal) ${ }^{3}$. Seus principais objetivos eram o desenvolvimento econômico e o fortalecimento das relações econômicas entre seus membros. Atualmente, a Cepal é formada 33 países da América Latina e outros 10 dos Continentes Europeu e Asiático e da América do Norte.

Em 1960, países da América do Sul ${ }^{4}$ reuniram-se em torno do ideal de aproximar suas economias, o que resultou na assinatura do Tratado de Montevidéu. Este instrumento internacional criou a Associação LatinoAmericana de Livre Comércio (ALALC), cujos objetivos principais eram a integração comercial de seus signatários (que visava à formação de uma área de livre comércio), a diversificação de suas economias e a diminuição de sua dependência em relação aos países denominados de primeiro mundo ${ }^{5}$. Seu tratado constitutivo previa, inicialmente, um prazo de 12 anos para a criação da zona de livre comércio, lapso posteriormente alterado pelo Protocolo de Caracas (1969), que o prolongou em oito anos.

${ }^{1}$ LOCATELLI, Cláudia Cínara. Mercosul: tribunal arbitral ou permanente? Curitiba: Juruá, 2003. p 18.

${ }^{2}$ PABST, Haroldo. Mercosul: direito da integração. Rio de Janeiro: Forense, 1998. p 7.

${ }^{3}$ Foi criada em 25 de fevereiro de 1948 pela Resolução 106(VI) do Conselho Econômico e Social. Na ocasião se chamava Comissão Econômica para a América Latina. Todavia, somente em 27 jul. 1984, passou a ter o nome atual.

${ }^{4}$ Com exceção do México, Guiana Francesa e Guiana.

5 FLORÊNCIO, Sérgio Abreu e Lima; ARAÚJO, Ernesto Henrique Fraga. MERCOSUR, proyecto, realidad y perspectivas. Trad. Maria del Carmen Hernández Gonçalves. Brasilia: Vest-Con, 1997. p. 31. 
Devido a problemas oriundos da instabilidade política na qual viviam alguns de seus membros, da inflexibilidade dos mecanismos de abertura comercial $^{6}$ e ante a impossibilidade de cumprimento dos prazos estabelecidos em seus instrumentos constitutivos, a ALALC foi extinta, vinte anos após sua criação. Em 12 de agosto de 1980, foi firmado o também o Tratado de Montevidéu, que criou a Associação Latino-americana de Integração (ALADI), em substituição à ALALC.

Na segunda metade dos anos 80, começou emergir um tímido, porém crescente intercâmbio econômico entre Brasil e Argentina ${ }^{7}$, haja vista que a necessidade de restabelecer suas economias, em especial devido aos grandes empréstimos contraídos por seus governos durante o período ditatorial, possibilitou uma saudável aproximação das duas nações vizinhas.

Instrumentos internacionais, tais como o Tratado de Cooperação Econômica, assinado em 1986, a Declaração de Foz do Iguaçu, de 1985 e o Tratado de Integração, Cooperação e Desenvolvimento (1988), uniam cada vez mais as economias do Brasil e da Argentina. Porém, foi a Ata de Buenos Aires, firmada em 06 de julho de 1990, instrumento de suma importância, vez que em seu seio se decide estabelecer um mercado comum. Não se pode olvidar que o Acordo de Complementação Econômica $n^{\circ} 14$, acordado no âmbito da ALADI entre Brasil e Argentina, para a melhor doutrina $^{8}$, também foi de grande valia para a conformação do Mercosul, inspirando o Tratado de Assunção.

\section{Criação e desenvolvimento do Mercosul}

\footnotetext{
${ }^{6}$ Ibidem, p. 31.

7 FLORÊNCIO, Sérgio Abreu e Lima; ARAÚJO, Ernesto Henrique Fraga. MERCOSUR, proyecto, realidad y perspectivas. Trad. Maria del Carmen Hernández Gonçalves. Brasilia: Vest-Con, 1997. p. 11.

${ }^{8}$ DREYZIN DE KLOR, Adriana. El Mercosur: generador de uma nueva fuente de derecho internacional privado. Buenos Aires: Zavalia, 1997. p 48.
} 
A República Argentina, a República Federativa do Brasil, a República do Paraguai e a República do Uruguai, aos 26 dias do mês de março de 1991, constituíram o Mercosul com a assinatura do Tratado de Assunção. Este instrumento estabelece de forma gradual a livre circulação de bens, serviços e fatores produtivos, a harmonização de legislações e a criação de uma tarifa externa comum. Em seu texto estavam previstas duas fases para a integração: uma provisória e outra definitiva.

Na primeira fase, que se estendeu até 31 de dezembro de 1994, vislumbrou-se a criação de um Programa de Liberação Comercial, a coordenação de políticas macroeconômicas e a adoção de uma tarifa externa comum, bem como acordos setoriais. Em 2004, com a entrada em vigor do Protocolo de Olivos, foi adotado um Sistema de Solução de Controvérsias para o Mercosul e criado o Tribunal Permanente de Revisão, cuja sede é a capital Paraguaia.

Passado um triênio da assinatura do Tratado de Assunção, com o fim da fase provisória, em dezembro de 1994, os Estados Partes assinaram o Protocolo de Ouro Preto, adicional àquele, dando ao Mercosul personalidade jurídica de direito internacional e estabelecendo em seu âmbito uma estrutura institucional, marcando o final de um período de transição.

Em 24 de julho de 1998, foi firmado o Protocolo de Ushuaia sobre o Compromisso Democrático no Mercosul. Este instrumento é de imensurável importância para o tema que será abordado neste trabalho, vez que trata do caráter democrático que devem assumir as instituições mercosulinas e sobre as medidas a serem tomadas em caso de ruptura da ordem democrática nos Estados partes do referido Protocolo.

Tendo em vista a crescente corrente integracionista e os benefícios de fazer parte de um Bloco Econômico, Bolívia e Chile passaram a integrar o Mercado Comum do Sul, como Membros Associados, porém, 
somente após cinco anos de vigência do Tratado de Assunção, conforme preconiza o artigo 20 desta norma. Ambos foram recepcionados, respectivamente, por meio das Decisões $n^{\circ}$. 14/96 e n ${ }^{\circ}$. 12/97 do Conselho Mercado Comum. A Venezuela, por seu turno, encontra-se em processo de adesão ao Bloco com o status de Estado Parte, nos termos da Decisão CMC $n^{0} .29 / 05$.

Mais recentemente, na Reunião Ordinária do Conselho do Mercado Comum, ocorrida no primeiro mês de 2007, na cidade do Rio de Janeiro, foi constituído, por meio da Decisão nº. 01/07, grupo ad hoc para definir os termos da incorporação da Bolívia ao Bloco, como Estado Parte.

Com a expansão do Bloco, surgiu uma crescente necessidade de acelerar a tramitação das normas emanadas do Mercosul nos Poderes Legislativos dos Estados, para que o processo de integração pudesse dar passos cada vez maiores e conferir a segurança advinda do respaldo jurídico das normas internalizadas por todos. Em adição, era necessário um meio capaz de dirimir as diferenças entre os Estados, harmonizar as legislações nacionais, e fomentar a cooperação inter-parlamentar. ${ }^{9}$ Tendo em vista estas demandas, o Conselho Mercado Comum aprovou em dezembro de 2005, o Protocolo Constitutivo do Parlamento do Mercosul.

\section{Rumo à constituição de um Parlamento Regional}

O Parlamento foi fruto de uma intensa atividade da Comissão Parlamentar Conjunta, em harmonia com os órgãos decisórios do bloco e da vontade política dos Estados Partes, em estabelecer um modelo de representação para o Mercosul. Nesse sentido, faremos um breve histórico do processo que levou à instalação do Parlasul.

${ }^{9}$ MERCOSUl. Decisão CMC $n^{\circ}$ 23/05. Protocolo Constitutivo do Parlamento do Mercosul. Montevidéu, 8 dez. 2005. Preâmbulo. 
Pode-se dizer que sua criação foi timidamente prevista pelo Tratado de Assunção, que ao instituir a Comissão Parlamentar Conjunta, trouxe à estrutura do Mercado Comum do Sul um órgão composto por parlamentares eleitos pelos nacionais dos Estados Partes. Este discreto animus persistiu, mas somente com a Decisão CPC s/n/91, aprovada no âmbito da II Reunião Parlamentar do Mercosul, manifestou-se pela primeira vez diretamente a decisão política de se criar um Parlamento para o bloco, vislumbrando-se a integração dos povos mercosulinos ${ }^{10}$.

Remonta ao preâmbulo da Resolução CPC nº. 02/97 o objetivo de se fortalecer a atuação parlamentar no processo de integração, visando à futura instalação de um Parlamento. Para tanto, foi conferida à Comissão Parlamentar Conjunta a atribuição de desenvolver as ações que se fizessem necessárias para facilitar esta instalação ${ }^{11}$. Para tanto, por força da Disposição $\mathrm{n}^{\circ}$. 14/99, a CPC iniciou estudos e trabalhos visando ao estabelecimento de uma agenda para a institucionalização do Parlamento ${ }^{12}$. Cabe mencionar que consta no Anexo II da Ata CPC $n^{0}$. 01/00, como item a ser debatido no seio desta Comissão, a reforma do Protocolo de Ouro Preto para a institucionalização do Parlamento ${ }^{13}$.

Em junho de 2000, os parlamentares dos Estados Membros reafirmaram seu "compromisso com a democracia representativa", por meio da Declaração de Santa Fér ${ }^{4}$. Nesse documento reconheceram os problemas gerados pela globalização e buscaram, em um contexto de desenvolvimento e expansão conjuntos, demonstrar que estavam em pleno processo de

${ }^{10}$ MERCOSUL. Decisão CPC S/N. II Reunião Parlamentar do Mercosul. Documento final (decisão política de criar o Parlamento). Buenos Aires, 20 set. 1991. art. $5^{\circ}$.

${ }^{11}$ Idem. Disposição CPC $n^{\circ}$. 02/97. Regimento da Comissão Parlamentar Conjunta. Montevidéu, 13 dez. 1997. art. $3^{\circ}$.

${ }^{12}$ Idem. Disposição CPC $n^{\circ}$. 14/99. Institucionalização do Parlamento do Mercosul. Montevidéu, 08 dez. 1999. art. $1^{\circ}$.

${ }^{13}$ Idem. Ata 01/00 da Comissão Parlamentar Conjunta do Mercosul. Montevidéu, 06-08 dez. 1999. Item A, Anexo II.

${ }^{14}$ Idem. Decisão CPC no . 03/00. Declaração de Santa Fé. Santa Fé, 28 jun. 2000. 
confecção de uma agenda para a constituição do almejado Parlasul. No mesmo ano, adotou-se a Disposição CPC nº. 35/00. Em seu anexo, estão presentes duas propostas de cronograma para a institucionalização do Parlamento. Os esforços para alcançar este fim foram divididos em fases, sendo a primeira denominada de "vontade política", a segunda "mecanismos de transição" e a última etapa culminaria na criação de um órgão supranacional $^{15}$.

A primeira proposta tratava da criação de um grupo ad hoc intergovernamental e a segunda versava sobre a criação de um Grupo Técnico Especializado da CPC para que este, na fase vontade política, pudesse estudar um projeto de recomendação ao Conselho Mercado Comum, com vistas à elaboração de uma agenda de um grupo ad hoc intergovernamental, que teria a atribuição de "definir uma etapa de estratégia política para a futura estrutura do Mercosul como pessoa supranacional”16. Ademais, de acordo com esta proposta, as Seções Nacionais da Comissão Parlamentar deveriam realizar reuniões com vistas a alcançar um entendimento político sobre a conveniência da criação de um órgão "supranacional parlamentar"17, bem como a formulação de estudo sobre a viabilidade econômica de se financiar uma campanha de divulgação para informar a população a respeito da criação de um órgão que os representasse em um nível supranacional. ${ }^{18}$

A importância da criação de um órgão representativo no qual possam participar os cidadãos mercosulinos foi reforçada pela Disposição CPC $n^{0}$. 05/02, que dispõe também sobre o grupo técnico encarregado de

${ }^{15}$ MERCOSUL. Disposição CPC $n^{\circ}$. 35/00. Agenda para a institucionalização do Parlamento do Mercosul. Porto Alegre, 09 nov. 2000. Anexo 2, Proposta 1.

${ }^{16}$ Ibidem, art. $2^{\circ}$, do Anexo 2, Proposta 2.

${ }^{17}$ Ibidem, art. $2^{\mathrm{o}}$, do Anexo 2, Proposta 2.

${ }^{18}$ Ibidem, art. 5o , do Anexo 2, Proposta 2. 
formular projetos que propiciassem a institucionalização do Mercosul por meio de a reforma do Protocolo de Ouro Preto ${ }^{19}$.

A respeito deste tema, ao final do ano de 2002, foi publicada uma norma mercosulina que recomenda a criação de um Comitê Ad Hoc que teria o objetivo de apresentar ao Conselho Mercado Comum informe avaliativo a respeito da reforma do $\mathrm{POP}^{20}$. No mesmo sentido, a Disposição CPC n ${ }^{\circ}$. 14/02 regula a forma e o prazo para a designação dos parlamentares que comporiam este comitê2 ${ }^{21}$ e trata das pautas comuns que deveriam ser adotadas pelas seções nacionais ${ }^{22}$, sendo que nestas estavam contempladas a realização de seminários cujo tema era a reforma do POP e a realização de consultas com os partidos políticos sobre a oportunidade e necessidade da criação do Parlasul.

Na reunião da Mesa Executiva da Comissão Parlamentar Conjunta do Mercosul, ocorrida na cidade de Montevidéu, em outubro de 2003, foi apresentado o Projeto de Acordo Interinstitucional CPC - CMC como primeira fase de instauração de um Parlamento Regional do Mercosul $^{23}$.

Na Declaração de Puerto Iguazú ${ }^{24}$ foi expresso o interesse dos presentes na reformulação da estrutura institucional do Mercosul, de forma a

19 MERCOSUL. Disposição CPC $n^{\circ}$. 05/02. Agenda para a institucionalização do Parlamento do Mercosul. Buenos Aires, 04 jul. 2002. art. $2^{\circ}$.

${ }^{20}$ Idem. Recomendação CPC $n^{\circ}$. 25/02. Recomendações da Comissão parlamentar Conjunta. Comitê Ad Hoc para a Institucionalização do Parlamento do Mercosul. Brasília, 05 dez. 2002.

${ }^{21}$ Idem. Disposição CPC $n^{o}$. 14/02. Comitê Ad Hoc para a Institucionalização do Parlamento do Mercosul. Brasília, 05 dez. 2002. art. $1^{\circ}$.

${ }^{22}$ Idem. Disposição CPC $\boldsymbol{n}^{\text {o }}$. 14/02. Comitê Ad Hoc para a Institucionalização do Parlamento do Mercosul. Brasília, 05 dez. 2002. art. $2^{\circ}$.

${ }^{23}$ Idem. Disposição CPC $n^{\circ}$. 08/03. Projeto de Acordo Interinstitucional CMC-CPC. Mesa Executiva da Comissão Parlamentar Conjunta do Mercosul. Montevidéu, 06 out. 2003. Anexo I.

${ }^{24}$ Idem. Decisão CPC nº 01/04. Declaração de Puerto Iguazú. Puerto Iguazú, 06-07 jul. 2004. 
proporcionar uma maior segurança jurídica ao Bloco, por meio de um direito de integração sólido, procedimentos eficazes de incorporação de normativos aos ordenamentos nacionais e um sistema de justiça eficiente. Neste contexto, o Parlamento do Mercosul assumiu o papel de "pilar de sustentação" contribuinte para o fortalecimento da democracia no Bloco, o qual gerará uma dimensão política ao Bloco, proporcionando uma consciência regional nos cidadãos.

Dando continuidade à criação do Parlamento do Mercosul, o CMC delegou à CPC a atribuição de realizar as ações necessárias para a instalação do Parlasul até a data de 31 de Dezembro de 2006, encarregandolhe da elaboração de um informe de atividades e da apresentação de um projeto de Protocolo Constitutivo do Parlamento do Mercosul, a ser submetido à sua consideração ${ }^{25}$. Para tanto, foram aprovadas duas importantes disposições na reunião da Mesa Executiva da Comissão Parlamentar Conjunta, realizada em março de 2005.

A Disposição CPC no. 02/05 deu início às atividades da Comissão Preparatória do Parlamento do Mercosul $^{26}$, cujas principais atribuições eram conduzir e monitorar a elaboração de projeto de Protocolo Constitutivo do Parlamento, negociar o texto do projeto com os Executivos, manter interface política com os Congressos Nacionais, monitorar e conduzir o cronograma de ação e de instalação física do Parlamento ${ }^{27}$. Por seu turno, a Disposição CPC nº 03/05 criou o Grupo Técnico de Alto Nível do

${ }^{25}$ MERCOSUL. Decisão CMC $n^{\circ}$. 49/04. Parlamento do Mercosul. Belo Horizonte, 16 dez. 2004.

26 Idem. Disposição CPC $n^{\circ}$. 02/05. Comissão Preparatória do Parlamento do Mercosul. Assunção, 30 mar. 2005. art. $1^{\circ}$.

27 Idem. Disposição CPC $n^{\circ}$. 02/05. Comissão Preparatória do Parlamento do Mercosul. Assunção, 30 mar. 2005. art. $3^{\circ}$. 
Parlamento do Mercosul, para auxiliar a Comissão Preparatória em suas atividades $^{28}$.

Em outubro de 2005, foi aprovada disposição referente às "bases do acordo político para a instalação do Parlamento do Mercosul”29 que veio coroar o trabalho até então desenvolvido pela CPC. No preâmbulo desta norma, está destacada a importância da inserção de um órgão representativo dos cidadãos mercosulinos na estrutura do Mercosul.

Dando prosseguimento aos trabalhos de instituição do Parlasul, em 08 de dezembro de 2005, foi aprovado o texto de seu Protocolo Constitutivo, por meio da decisão do Conselho Mercado Comum nº. 23/05.

\section{Protocolo Constitutivo do Parlamento do Mercosul}

Após inúmeros debates e reuniões, realizados no âmbito do Mercosul, configurou-se um projeto de Protocolo Constitutivo que convergia para a visão dos diversos atores presentes no processo de elaboração e criação do tão aguardado Parlamento regional.

No âmbito nacional, a aprovação do referido instrumento pelo Poder Legislativo se deu de forma célere, sendo encaminhado ao Congresso Nacional, em 24 de maio de 2006, por meio da Mensagem n ${ }^{\circ}$ 408/2006, que submete à apreciação deste texto do Protocolo Constitutivo do Parlamento do Mercosul (PCPM), nos termos do artigo 49, inciso I, combinado com artigo 84, inciso VIII, da Carta Magna.

O PCPM foi recebido pela Mesa Diretora da Câmara dos Deputados e convertido em Projeto de Decreto Legislativo, recebendo o

${ }^{28}$ Idem. Disposição CPC $n^{o}$. 03/05. Grupo Técnico de Alto Nível Parlamento do Mercosul. Assunção, 30 mar. 2005. art. $1^{\circ}$.

29 Idem. Disposição CPC $n^{\circ}$. 11/05. Parlamento do Mercosul. Reunião Plenária Extraordinária da Comissão Parlamentar Conjunta. Buenos Aires, 11 out. 2005. 
número 2.266/2006. A tramitação nesta casa se deu da seguinte forma: a Comissão Parlamentar Conjunta do Mercosul sugeriu, em 06 de junho, a aprovação do referido PDC. Por seu turno, no dia seguinte, a Comissão de Relações Exteriores e de Defesa Nacional também opinou por sua aprovação. Em parecer datado de $1^{\circ}$ de agosto, a Comissão de Constituição e Justiça votou pela constitucionalidade, juridicidade, técnica legislativa e, na análise meritória, pela aprovação do Projeto de Decreto Legislativo ${ }^{30}$. Em 05 de agosto de 2006, o PDC foi aprovado em Plenário e encaminhado ao Senado Federal $^{31}$ por meio do Ofício SGM-P n ${ }^{\circ}$. 1602/2006. No dia 16 daquele mês, foi transformado no Decreto Legislativo nº 408/2006 e publicado no Diário oficial da União ${ }^{32}$.

O Senado Federal, ao receber em seu protocolo legislativo a referida norma mercosulina, nomeou-a e numerou como PDS nº. 410/2006. Consta na Ata do Plenário, de 05 de agosto, a abertura de prazo para recebimento de emendas, sendo que findos cinco dias, a Comissão de Relações Exteriores e Defesa Nacional deveria emitir opinião sobre a matéria. Nesta mesma data, o relator concluiu favoravelmente à aprovação do PDS em pauta $^{33}$ que, em votação, na mesma ocasião, restou aprovado ${ }^{34}$. Sua aprovação se deu no dia 12 daquele mesmo mês ${ }^{35}$. Por fim, aos trinta dias do mês de abril de 2007, foi promulgado pelo Decreto Presidencial nº 6.105 .

O Protocolo Constitutivo do Parlamento do Mercosul tornou-se um marco do movimento de integração, ao dar vida ao Parlasul e dispor sobre o sistema de representação a ser adotado em seu âmbito, bem como suas

${ }^{30}$ BRASIL. Diário da Câmara dos Deputados. 04 ago. 2006. p. 40024 COL 02, Letra A.

${ }^{31}$ Idem. Diário da Câmara dos Deputados. 06 set. 2006. p. 43592 COL 01.

${ }^{32}$ Idem. Diário Oficial da União. 13 set. 2006. p. 01 COL 02; Diário da Câmara dos Deputados. 13 set. 2006. p. 44414 COL 01.

${ }^{33}$ Idem. Diário do Senado Federal. 06 set. 2006. p. 28030 - 28032.

${ }^{34}$ Idem. Diário do Senado Federal. 06 set. 2006. p. 27945 - 27959.

35 Idem. Diário do Senado Federal. 13 set. 2006. p. 28655-28656; BRASIL. Diário Oficial da União: Especial. 13 set. 2006. p. 00001. 
competências, princípios regentes, atribuições parlamentares e forma de eleição de seus membros.

\section{Implementação e Início das atividades do Parlamento}

Conforme previsto no artigo $1^{\circ}$, do PCPM, em 14 de dezembro de 2006, na cidade de Brasília, foi constituído o Parlamento do Mercosul, em Sessão Solene, no Congresso Nacional, liderada pelo Presidente do Senado Federal, com participação do Presidente da República, estando presentes membros e presidentes das seções nacionais e Comissão Parlamentar Conjunta, dentre outras autoridades.

Na Sessão Constitutiva do PM, salientou-se nos discursos dos presentes a importância deste órgão para a união da América Latina e para o fortalecimento da democracia na região. Demonstraram-se no decorrer do evento a relevância e importância deste órgão representativo dos povos mercosulinos para toda a região ${ }^{36}$ e para a conscientização dos cidadãos dos Estados membros do Mercosul, bem como se destacou a necessidade de uma unidade para Bloco.

Dando continuidade à instalação deste novo órgão, conforme calendário tentativo da Secretaria do Mercosul, a Primeira e Segunda Sessões do Parlamento do Mercosul foram realizadas, nos dias 7 e 8 de maio de 2007, na cidade de Montevidéu. Nestas duas primeiras sessões, foram eleitas a Mesa Diretora (composta por um representante de cada Estado Membro) e

\footnotetext{
${ }^{36}$ Sobre a importância da criação de um órgão parlamentar no Mercosul para a adoção de políticas públicas regionais no âmbito do Mercosul ver MARTINS, Helena; RIBEIRO, Elisa; SANTORO, Maurício. Parlamento do Mercosul: forma de organização e perspectivas à participação social e às políticas públicas. Observatório Político Sul-Americano. Observador On-line v. 2, n. 12, dez 2007. Disponível em: <http://observatorio.iuperj.br/observador.php>. Acesso em: $20 \mathrm{dez}$. 2007.
} 
criadas as comissões temporárias de elaboração do Regimento Interno e de Agenda Política do Parlamento do Mercosul.

A Terceira Sessão Ordinária realizou-se, em 25 de junho de $2007^{37}$, na capital uruguaia, onde pela primeira vez, houve a apresentação de um relatório de gestão da Presidência Pro Tempore do Mercosul ao Plenário do Parlamento. Nesta ocasião, o Ministro de Relações Exteriores da República do Paraguai apresentou o seu relatório, ativando uma das principais competências do Parlasul, conforme o art. $4^{\circ}$, inciso 6, do Protocolo Constitutivo.

Na mesma oportunidade, foram aprovadas, ainda, uma proposta de declaração de apoio às posições assumidas pelos Estados Partes do bloco nas negociações da OMC e manifestando o entendimento de que a Rodada de Doha, somente chegará a um bom termo, se levar à liberação significativa do comércio agrícola e à correção das assimetrias nos fluxos de comércio mundial; e uma proposta de declaração de respaldo à República Argentina na disputa de soberania concernente às Ilhas Malvinas.

Dando continuidade à sessão, o Plenário aprovou a Agenda Política do Parlasul, destacando como temas prioritários, o diagnóstico da situação atual do Mercosul, o relacionamento do Parlasul com o CMC, integração energética, assimetrias, aqüífero Guarani e recursos naturais, erradicação do trabalho infantil, Coordenação macroeconômica e Banco do Sul, política regional de defesa dos direitos humanos, livre circulação de obras de arte e espetáculos, entre outros temas. Ao fim da sessão, houve a transmissão da Presidência do Parlamento do Paraguai ao Uruguai. Ficou estabelecido que até o final de 2008, haveria rotação da Presidência, em coincidência com a Presidência Pro Tempore do Bloco.

37 MERCOSUL. Ata PM 03/07. Ata da III Seção do Parlamento do Mercosul. Disponível em: <http://www.parlamentodelmercosur.org/archivos/Acta\%2003\% 202007\%20ES.pdf>. Acesso em: 13 jun. 2008. 
A Quarta Sessão Ordinária, realizada nos dias 6 e 7 de agosto ${ }^{38}$, foi marcada pela aprovação do Regimento Interno do órgão e da assinatura do primeiro Acordo Interinstitucional, na ocasião, entre o Parlamento e o Foro Consultivo Econômico-Social. De acordo com este documento, as duas instituições se comprometiam a realizar reuniões semestrais conjuntas e a realizarem consultas mútuas. Na mesma sessão, o então Presidente apresentou seu plano de trabalho para a Presidência, ressaltando alguns pontos: fortalecimento do direito do Mercosul, déficit democrático e cidadania regional, soberania compartilhada, desenvolvimento regional, e comunidade sul-americana.

Com respaldo no recém-aprovado Regimento Interno, manifestou-se a criação do primeiro grupo político no Parlasul, denominado de "Partido Nacional". Ademais, foram criadas também duas comissões especiais: a de Acompanhamento dos Programas de Luta contra a Febre Aftosa e a Comissão de Orçamento de 2008.

Em 3 de setembro de 2007, na Quinta Sessão Ordinária ${ }^{39}$, os parlamentares resolveram entre outras coisas, assuntos internos. Chegou-se a um acordo político entre as delegações nacionais sobre a composição das comissões permanentes. Coube à delegação argentina a presidência da Comissão de Assuntos Jurídicos e Institucionais, bem como a da Comissão de Trabalho, Políticas de Emprego, Seguridade Social e Economia Social; as vice-presidências das Comissões de Assuntos Econômicos, Comerciais,

38 MERCOSUL. Ata PM 04/07. Ata da IV Seção do Parlamento do Mercosul. Disponível em: <http://www.parlamentodelmercosur.org/archivos/Acta\%2004\% 202007\%20ES.pdf>. Acesso em: 13 jun. 2008.

39 Idem. Ata PM 06/07. Ata da V Seção do Parlamento do Mercosul. Disponível em: $<$ http://www.parlamentodelmercosur.org/archivos/Acta\%2006\%202007\%20ES.pd f>. Acesso em: 13 jun. 2008. 
Tributários e Monetários, de Assuntos Internacionais e de Planejamento Estratégico; e de Orçamento e Assuntos Internos.

À delegação brasileira, coube as Presidências das Comissões de Assuntos Econômicos, Comerciais, Tributários e Monetários; de Educação; e de Desenvolvimento Regional Sustentável; e as Vicepresidências das Comissões de Assuntos Internos, Seguridade e Defesa; e de Infra-estrutura e Recursos Energéticos.

Com os parlamentares do Paraguai ficaram as Presidências das Comissões de Assuntos Internacionais, Inter-regionais e de Planejamento Estratégico; e de Orçamento e Assuntos Internos; e as Vice-presidências das Comissões de Desenvolvimento Regional Sustentável; e de Cidadania e Direitos Humanos.

E a delegação uruguaia ficou com as Presidências das Comissões de Cidadania e Direitos Humanos; de Assuntos Internos, Seguridade e Defesa, e de Infra-estrutura e Recursos Energéticos; e as Vicepresidências das Comissões de Assuntos Jurídicos e Institucionais; de Educação; e de Trabalho, Políticas de Emprego, Seguridade Social e Economia Social.

Estabeleceu-se, por acordo entre os membros, que os países com três presidências, Brasil e Uruguai, deverão ceder uma presidência à delegação da Venezuela, no momento em que o país efetive seu ingresso no Mercosul. Do mesmo modo, Argentina e Uruguai, que têm três Vicepresidências cada um, deverão ceder uma vice-presidência à nova delegação incorporada.

Continuando sobre temas internos, os parlamentares trataram, ainda, nesta V Sessão sobre o orçamento do órgão para o ano de 2008. Ressaltou-se a necessidade de ter um orçamento austero e uma estrutura mínima de funcionários para os meses vindouros. Sendo assim, aprovou-se 
um orçamento de cerca de 1 milhão de dólares, prevendo uma quantidade de 25 funcionários.

Antes de encerrar a sessão, o Plenário do Parlasul recebeu um Informe do Grupo de Alto Nível de Estratégia do Mercosul de Crescimento do Emprego (GANEMPLE). Vale ressaltar que o Parlasul está apto, e parece ser uma excelente oportunidade, à recepção de informes das autoridades do bloco, assim, este corpo parlamentar tem a possibilidade de discutir e acompanhar os principais temas da agenda regional.

Em 8 de outubro de 2007, realizou-se a VI Sessão do Parlasul $^{40}$. Na eminência das eleições presidenciais e legislativas na Argentina, esta sessão não pode produzir atos normativos devido ao baixo quorum, porém os trabalhos seguiram com a apresentação pela presidência dos resultados da reunião realizada na cidade boliviana de Cochabamba, com integrantes do Parlamento Andino. Em seguida, o plenário debateu proposta de declaração de respaldo às negociações da Venezuela, na condição de mediadora, do acordo humanitário entre as FARC e a Colômbia.

No mês de novembro, o Parlasul realizou sua VII Sessão Ordinária $^{41}$. Após as eleições na Argentina, o espectro político no Cone Sul pareceu mais bem definido, pelo menos até as eleições que viriam no Paraguai, em abril de 2008. Nesta sessão se aprovaram duas importantes declarações. A primeira, que havia iniciado a discussão na sessão anterior, de respaldo às negociações no caso Farc/Colômbia ${ }^{42}$. E a segunda, sobre o

\footnotetext{
${ }^{40}$ MERCOSUl. Ata PM 07/07. Ata da VI Seção do Parlamento do Mercosul. Disponível em: <http://www.parlamentodelmercosur.org/archivos/Acta\%2007\% 202007\%20ES.pdf>. Acesso em: 13 jun. 2008.

${ }^{41}$ Idem. Ata PM 08/07. Ata da VII Seção do Parlamento do Mercosul. Disponível em: <http://www.parlamentodelmercosur.org/archivos/Acta\%2008\%202007\%20versión \%2002.pdf >. Acesso em: 13 jun. 2008.

42 Idem. Declaração PM 03/07. Declaración de respaldo a las gestiones de un acuerdo humanitario en la República de Colombia. Montevidéu, 19 nov. 2007.
} 
genocídio do povo armênio ${ }^{43}$. Esta última foi o primeiro ato normativo aprovado no Parlasul, cuja origem e gestão para aprovação teve impulso predominante da sociedade civil, no caso pelo Conselho da Causa Armênia do Uruguai.

Em razão do fim do período legislativo, que se encerra no dia 15 de dezembro de cada ano e começa no dia 15 de fevereiro, a sessão de dezembro de 2007 foi convocada de forma extraordinária, já que se realizou no dia 18 daquele mês. Naquela sessão se procedeu à transmissão da Presidência do Parlamento do Mercosul do Uruguai à Argentina e foram aprovadas três declarações.

A primeira declaração versava sobre a situação política em que se encontrava a Bolívia, com as tentativas de autonomia de vários territórios naquele país ${ }^{44}$. O documento aprovado declarava o firme apoio do Parlamento regional ao regime institucional da República da Bolívia, incluindo o reconhecimento e a estabilidade das autoridades e instituições eleitas pelo povo boliviano. A segunda apoiava as recentes eleições ocorridas na Argentina, como exemplo de fortalecimento do processo democrático na região ${ }^{45}$ e a última propugnava pela criação de mecanismos que garantissem condições de sobrevivência às famílias, vítimas de tragédia ocorrida no Peru $^{46}$.

${ }^{43}$ MERCOSUL. Declaração PM 04/07. Condena al genocidio del pueblo armeno. Montevidéu, 19 nov. 2007.

${ }^{44}$ MERCOSUL. Declaração PM 05/07. Que declara el firme apoyo del Parlamento del Mercosur al Régimen Institucional de la República de Bolivia incluyendo el reconocimiento de las autoridades e instituciones electas por el pueblo boliviano. Montevidéu, 18 dez. 2007.

${ }^{45}$ Idem. Declaração PM 06/07. Declara a sua consideração pela eleição da senhora Cristina Fernandez de Kirschner para a Presidência da Republica Argentina. Montevidéu, 18 dez. 2007.

${ }^{46}$ Idem. Declaração PM/2007. Creación de mecanismos efectivos para la protección y salvaguarda de las condiciones de sobre vivencia de las familias que viven 
O ano de 2008 teve início com uma intensa agenda no Parlamento do Mercosul. As comissões permanentes já estavam funcionando e o Parlamento começou a ter uma dinâmica própria e ativa.

Na VIII Sessão Ordinária, realizada em março deste ano $^{47}$, aprovou-se um Relatório da Comissão Especial de Febre Aftosa, mostrando um panorama da situação epidêmica na região, além das medidas estatais que estão sendo tomadas. Ademais, aprovaram-se quatro declarações: sobre Acordo de Gratuidade de Vistos para estudantes e docentes dos Estados Partes; a segunda, de adesão à implementação da iniciativa "América Latina e Caribe sem fome 2025”; a terceira, sobre a resolução dos conflitos pela via diplomática multilateral na América do Sul; e a última, de solidariedade humanitária com os seqüestrados na Colômbia. Iniciou-se o debate de uma declaração de apoio à criação do Conselho Sul-americano de Defesa, mas a mesma foi encaminhada para a Comissão de Assuntos Interiores e Defesa, para melhor análise.

Na sessão ordinária, realizada em abril de 2008, a nona desde a criação do Parlasul, foram aprovados vários documentos. As Sessões Plenárias começaram a se realizar durante dois dias, impondo uma agenda mais extensa. Além de declarações de apoio a iniciativas regionais ${ }^{48}$, ao

momentos dramáticos por causa de la tragedia ocurrida en la República del Perú. Montevidéu, 18 dez. 2007.

47 MERCOSUL. Ata PM 03/08. Ata da VIII Seção do Parlamento do Mercosul. Disponível em: <http:/www.parlamentodelmercosur.org/archivos/ACTA\%20VIII \%20SESION\%20(31MARZ0\%202008)\%20CORREGIDA.pdf>. Acesso em: 13 jun. 2008.

${ }^{48}$ Idem. Declaração PM 05/08. Que declara del interés del parlamento del mercosur la iniciativa de los gobiernos de dos importantes regiones que componen este bloque, durante el "primer encuentro de gobiernos del noroeste argentino y del noreste brasilero”. Montevidéu, 29 abr. 2008; Idem. Declaração PM 07/08. Que declara su adhesión a la conformación del frente de Parlamentarios del Mercosur por los derechos de las personas con capacidades diferenciadas en la región. Montevidéu, 29 abr. 2008. 
governo eleito do Presidente Lugo do Paraguai $^{49}$ e de realização de seminários $^{50}$, vale destacar a criação de uma comissão temporária para investigar denúncias de violação dos Direitos Humanos no Paraguai e uma declaração de solidariedade com cidadãos cubanos detidos nos Estados Unidos $^{51}$.

\section{Considerações finais}

Parte da população de nossos países se pergunta: para que nos servirá um Parlamento do Mercosul?

O Parlamento do Mercosul foi criado, em 08 de dezembro de 2005, por meio da Decisão CMC n ${ }^{0}$. 23/05, a qual aprovou seu Protocolo Constitutivo. A criação deste órgão transformou-se num marco do movimento de integração, vez que ele inova ao trazer ao Mercosul uma nova forma de integração: a política. Isso se dá pelo fato de que ele será um meio para o exercício da democracia no órgão e um espaço para o debate pelos particulares dos temas ligados ao Bloco, conferindo um caráter eminentemente representativo aos cidadãos do Mercosul.

Ademais, este órgão tem a função de superar ou, ao menos, diminuir o déficit democrático ${ }^{52}$ no qual vive o movimento integracionista, proporcionando uma maior interface entre os particulares e os órgãos do Mercosul, a partir da geração de normas e decisões mais coesas com a

49 Idem. Declaração PM 08/08. Felicitação ao Presidente eleito da República do Paraguai. Montevidéu, 29 abr. 2008.

50 Idem. Declaração PM 09/08. Que declara de interés regional la realización del congreso de la reforma universitaria latinoamericana a llevarse a cabo del 11 al 15 junio en la ciudad de Córdoba, Argentina. Montevidéu, 29 abr. 2008.

51 Idem. Declaração PM 06/08. Solidaridad con los ciudadanos cubanos detenidos en los estados unidos. Montevidéu, 29 abr. 2008.

${ }^{52}$ Ver RIBEIRO, Elisa. Democracia regional: o parlamento do Mercosul e a abertura de novos espaços de participação para a sociedade civil. Brasília, 2008. Trabalho de Conclusão (Graduação em Direito)-Centro Universitário de Brasília. 
realidade social na qual vivemos, semeando uma consciência de cidadania e um sentimento de mercosulidade nos indivíduos.

Hoje, são tomadas várias decisões no âmbito do bloco que afetam diretamente a vida dos cidadãos dos Estados partes. Nem todos sabem, mas qualquer cidadão do bloco pode contribuir para a seguridade social em qualquer Estado parte e obter os benefícios sociais correspondentes, bem como sua posterior aposentadoria - Acordo Multilateral de Seguridade Social do MERCOSUL. Os estudantes também podem ter os seus diplomas reconhecidos em diferentes níveis nos demais Estados Partes, de acordo com várias normativas vigentes.

Mas, o exemplo mais tangível a nosso ver, é com respeito às alíquotas de importação no comércio intra-zona. No Brasil, parte do trigo que é utilizado para a fabricação do pão, consumido por milhões de brasileiros, provêm do mercado argentino. Esse trigo chega ao padeiro brasileiro com alíquota zero na taxa de importação. O pãozinho que todo brasileiro come ou qualquer outro alimento que tenha como insumo um produto que se beneficia da redução tarifária obtém uma sensível redução na composição do preço final. Nesse sentido, surge a pergunta: algo que afeta diretamente ao bemestar, ao direito de alimentação, de sobrevivência do cidadão, não deve ser decidido também por representantes eleitos diretamente pelo povo?

Atualmente, as decisões no bloco são tomadas pelo que chamamos de órgãos decisórios, compostos em sua totalidade por funcionários dos Poderes Executivos do bloco. No momento de formulação e tomada de decisão, não há nenhuma interferência de representante parlamentar eleito diretamente pelo cidadão de algum dos Estados partes. Uma pequena parte dessas decisões são submetidas à aprovação legislativa pelas Casas legislativas nacionais. O povo mercosulino não tem o direito de 
decidir sobre o seu próprio futuro? Sobre decisões que afetam diretamente as suas vidas?

O Parlamento do Mercosul, como órgão de representação direta regional, vem justamente suprir esse déficit democrático na tomada de decisão do bloco. O povo mercosulino, por meio de seu representante eleito, como já o fez o Paraguai, ao eleger por primeira vez Parlamentares do Mercosul, poderá, finalmente, influir no processo decisório do bloco.

Os benefícios trazidos por este órgão extrapolam os objetivos da formação de um mercado comum, gerando uma sólida integração econômica, pois na medida em que os temas são debatidos em seu âmbito, as decisões que são geradas passam a refletir a vontade de todos os povos do bloco, demonstrando perante os demais atores internacionais, uma maior segurança nos acordos celebrados pelo Mercosul. Desta forma, teremos mais força e coesão nas negociações internacionais, ganhando confiança e mercados.

\section{A Parliament for Mercosur: the political and historical process of its creation}

\section{Abstract}

In this paper it is remembered the history from the beginning of Mercosur until the creation of its Regional Parliament so we could present its activities which have recently started to be developed by this Mercosur's new body. Thus, a brief retrospective of the integration movement that ocurred Latin American countries is promoted. Initially, bringing up the attempts to promote bilateral economic agreements, through the initiatives to conform free trade areas and culminating in the current state where the Common 
Market of the South. Thus, you can understand the real importance of this parliamentary body has for Mercosur.

Key words: International Relations. Regional Integration models. Mercosur Parliament.

\section{Referências}

BRASIL. Diário da Câmara dos Deputados. 04 ago 2006. p. 40024 COL 02, Letra A.

. Diário da Câmara dos Deputados. 06 set. 2006. p. 43592. COL 01.

. Diário da Câmara dos Deputados. 13 set. 2006. p. 44414 COL 01.

. Diário Oficial da União. 13 set. 2006. p. 01 COL 02.

. Diário Oficial da União: Especial. 13 set. 2006. p. 00001.

. Diário do Senado Federal. 06 set. 2006. p. 28030-28032.

. Diário do Senado Federal. 06 set. 2006. p. 27945-27959.

. Diário do Senado Federal. 13 set. 2006. p. 28655-28656.

CASAL, Oscar. El camino hacia el parlamento del Mercosur: analisis y propuestas. Cidade: Friedrich Ebert Stiftung, ano.

DREYZIN DE KLOR, Adriana. El Mercosur: Generador de uma nueva fuente de derecho internacional privado. Buenos Aires: Zavalia, 1997.

FLORÊNCIO, Sérgio Abreu e Lima; ARAÚJO, Ernesto Henrique Fraga. MERCOSUR, proyecto, realidad y perspectivas. Trad. Maria del Carmen Hernández Gonçalves. Brasilia: Vest-Con, 1997.

FUNDACIÓN KONRAD ADENAUER; COMISIÓN PARLAMENTARIA CONJUNTA DEL MERCOSUR. Hacia el Parlamento del Mercosur. Montevidéu: Konrad-Adenauer- Stiftung, 2006. 
LOCATELLI, Cláudia Cínara. Mercosul: tribunal arbitral ou permanente? Curitiba: Juruá, 2003.

MARTINS, Helena; RIBEIRO, Elisa. SANTORO, Maurício. Parlamento do Mercosul: forma de organização e perspectivas à participação social e às políticas públicas. Observatório Político Sul-Americano. Observador On-line v. 2, n. 12, dez 2007. Disponível em: <http://observatorio.iuperj.br/ observador.php>. Acesso em: 20 dez. 2007.

MERCOSUL. Ata 01/00 da Comissão Parlamentar Conjunta do Mercosul. Montevidéu, 06/08 dez. 1999.

Ata PM 03/07. Ata da III Seção do Parlamento do Mercosul. Disponível em: <http://www.parlamentodelmercosur.org/archivos/Acta\% 2003\%202007\%20ES.pdf $>$. Acesso em: 13 jun. 2008.

Ata PM 04/07. Ata da IV Seção do Parlamento do Mercosul. Disponível em: <http://www.parlamentodelmercosur.org/archivos/Acta\% 2004\%202007\%20ES.pdf>. Acesso em: 13 jun. 2008.

Ata PM 06/07. Ata da V Seção do Parlamento do Mercosul. Disponível em: <http://www.parlamentodelmercosur.org/archivos/Acta\% 2006\%202007\%20ES.pdf>. Acesso em: 13 jun. 2008.

Ata PM 07/07. Ata da VI Seção do Parlamento do Mercosul. Disponível em: <http://www.parlamentodelmercosur.org/archivos/Acta\% 2007\%202007\%20ES.pdf >. Acesso em 13 de junho de 2008.

Ata PM 08/07. Ata da VII Seção do Parlamento do Mercosul. Disponível em: <http://www.parlamentodelmercosur.org/archivos/Acta\% 2008\%202007\%20versión\%2002.pdf>. Acesso em 13 de junho de 2008.

Ata PM 03/08. Ata da VIII Seção do Parlamento do Mercosul. Disponível em: <http://www.parlamentodelmercosur.org/archivos/ACTA\% 20VIII\%20SESION\%20(31MARZ0\%202008)\%20CORREGIDA.pdf $>$. Acesso em 13 de junho de 2008. 2000.

. Decisão CPC nº. 03/00. Declaração de Santa Fé. Santa Fé, 28 jun. . Decisão CMC n. 49/04. Parlamento do Mercosul. Belo Horizonte, 16 dez. 2004. 
Decisão CMC $n^{\circ}$ 23/05. Protocolo Constitutivo do Parlamento do Mercosul. Montevidéu, 8 dez. 2005.

. Decisão CPC S/N. II Reunião Parlamentar do Mercosul. Documento final (decisão política de criar o Parlamento). Buenos Aires, 20 set. 1991.

. Decisão CPC ño. 01/04. Declaração de Puerto Iguazú. Puerto Iguazú, 06/07 jul. 2004.

. Declaração PM 03/07. Declaración de respaldo a las gestiones de un acuerdo humanitario en la República de Colombia. Montevidéu, 19 nov. 2007.

. Declaração PM 04/07. Condena al genocídio del pueblo armeno. Montevidéu, 19 nov. 2007.

. Declaração PM 05/07. Que declara el firme apoyo del Parlamento del Mercosur al Régimen Institucional de la República de Bolivia incluyendo el reconocimiento de las autoridades e instituciones electas por el pueblo boliviano. Montevidéu, 18 dez. 2007.

Declaração PM 06/07. Declara a sua consideração pela eleição da senhora Cristina Fernandez de Kirschner para a Presidência da Republica Argentina. Montevidéu, 18 dez. 2007.

. Declaração PM/2007. Creación de mecanismos efectivos para la protección y salvaguarda de las condiciones de sobre vivencia de las familias que viven momentos dramáticos por causa de la tragedia ocurrida en la República del Perú. Montevidéu, 18 dez. 2007.

. Declaração PM 05/08. Que declara del interés del parlamento del mercosur la iniciativa de los gobiernos de dos importantes regiones que componen este bloque, durante el "primer encuentro de gobiernos del noroeste argentino y del noreste brasilero”. Montevidéu, 29 abr. 2008.

. Declaração PM 06/08. Solidaridad con los ciudadanos cubanos detenidos en los estados unidos. Montevidéu, 29 abr. 2008.

. Declaração PM 07/08. Que declara su adhesión a la conformación del frente de Parlamentarios del Mercosur por los derechos de las personas con capacidades diferenciadas en la región. Montevidéu, 29 abr. 2008. 
Declaração PM 08/08. Felicitação ao Presidente eleito da República do Paraguai. Montevidéu, 29 abr. 2008.

. Declaração PM 09/08. Que declara de interés regional la realización del congreso de la reforma universitaria latinoamericana a llevarse a cabo del 11 al 15 junio en la ciudad de Córdoba, Argentina. Montevidéu, 29 abr. 2008

. Disposição CPC $n^{o}$. 02/97. Regimento da Comissão Parlamentar Conjunta. Montevidéu, 13 dez. 1997.

Disposição CPC $n^{\circ}$. 14/99. Institucionalização do Parlamento do Mercosul. Montevidéu, 08 dez. 1999.

. Disposição CPC $n^{0}$. 35/00. Agenda para a institucionalização do Parlamento do Mercosul. Porto Alegre, 09 nov. 2000.

. Disposição CPC $n^{0}$. 05/02. Agenda para a institucionalização do Parlamento do Mercosul. Buenos Aires, 04 jul. 2002.

. Disposição CPC nº. 14/02. Comitê Ad Hoc para a Institucionalização do Parlamento do Mercosul. Brasília, 05 dez. 2002.

. Disposição CPC $n^{\circ}$. 08/03. Projeto de Acordo Interinstitucional CMC-CPC. Mesa Executiva da Comissão Parlamentar Conjunta do Mercosul. Montevidéu, 06 out. 2003.

. Disposição CPC $n^{0}$. 02/05. Comissão Preparatória do Parlamento do Mercosul. Assunção, 30 mar. 2005.

. Disposição CPC no . 03/05. Grupo Técnico de Alto Nível Parlamento do Mercosul. Assunção, 30 mar. 2005.

. Disposição CPC $n^{\circ}$. 11/05. Parlamento do Mercosul. Reunião Plenária Extraordinária da Comissão Parlamentar Conjunta. Buenos Aires, 11 out. 2005.

Protocolo de Ouro Preto. Ouro Preto, 17 dez. de 1994.

- Recomendação CPC $n^{o}$. 25/02. Recomendações da Comissão parlamentar Conjunta. Comitê Ad Hoc para a Institucionalização do Parlamento do Mercosul. Brasília, 05 dez. 2002. 
Regimento Interno do Parlamento do Mercosul. Montevidéu, 7 ago.

2007.

. Tratado de Assunção. Assunção, 26 mar. 1991.

PABST, Haroldo. Mercosul: direito da integração. Rio de Janeiro: Forense, 1998.

RIBEIRO, Elisa. Democracia regional: o parlamento do Mercosul e a abertura de novos espaços de participação para a sociedade civil. Brasília, 2008. Trabalho de Conclusão (Graduação em Direito)-Centro Universitário de Brasília.

VENTURA, Deisy; PEROTTI, Alejandro D. El processo legislativo del Mercosur. Montevideo: Konrad-Adenauer-Stiftung A.C., 2004. 